\title{
Chapter 11 \\ Outsourced Enforcement: Improving the Public Accountability of Building Inspectors
}

\author{
Nader Naderpajouh, Rita Peihua Zhang, and Jan Hayes
}

\begin{abstract}
Regulatory enforcement of building safety and quality has been outsourced with a move to partially privatised building inspectors in both the UK and Australia. The Grenfell Tower fire and other near misses in Australia highlight the problems this has introduced. This chapter reviews the role of building inspectors using a public administration accountability framework and recommends structural changes to improve safety for occupants of high-rise buildings.
\end{abstract}

Keywords Public accountability - Building inspection - Building regulation • Privatisation · Grenfell Tower

\subsection{Introduction}

The high-rise building construction sector has seen several high-profile accidents in recent years in the UK, Dubai, China, France, South Korea and Australia. The consequences of these events (both realised and potential) demonstrate that highrise buildings are effectively a kind of hazardous infrastructure and yet regulation of safety in high-rise construction has more in common with domestic building construction than with regulation of safety in other hazardous industries. Along with trends to performance-based regulation, a recent key factor has been privatisation of building inspection activities where inspection has been effectively outsourced from government to the private sector. Multiple accident investigations and industry reviews have noted this as a problem and yet solutions remain elusive.

This chapter draws on theories of public sector accountability to show that the issues are structural and so not amenable to solutions simply targeting skills and competency of building inspectors individually as has typically been the case.

\footnotetext{
N. Naderpajouh $(\bowtie) \cdot$ R. P. Zhang $\cdot$ J. Hayes

RMIT University, Melbourne, Australia

e-mail: nader.naderpajouh@sydney.edu.au

N. Naderpajouh

The University of Sydney, Sydney, Australia
} 


\subsection{Effective Regulation and Effective Regulators}

The building sector is controlled by regulations which are legal instruments intended to ensure provision of socially acceptable levels of health, safety and welfare of building occupants and users [7]. As such, building regulations specify regulatory controls over the design, construction, operation and demolition of buildings, addressing various aspects such as structural integrity, fire safety, heating, lighting, ventilation, sanitary facilities and indoor air quality [7]. Traditionally, building regulations were prescriptive and expressed as detailed descriptions of how each building component or system must be constructed.

Many countries have transitioned from a prescriptive-based building regulatory regime to a performance-based building regulatory regime [13]. A performancebased building code specifies the criteria to be achieved as an outcome, rather than prescribing the specific manner in which a building is to be constructed. Parallel to the common justifications of efficiency in neoliberalism, the underlying motivation of such changes in the building industry included "reducing regulatory burden, reducing costs to the industry and public, increasing innovation and flexibility in design and construction, and being better positioned to address emerging issues" [6].

Regulated standards for construction are one thing, but in a competitive environment, regulation is of limited effectiveness without some degree of common oversight and enforcement activities to provide construction companies with an incentive to comply. As has been found in other industries, moving to performance-based regulation requires highly skilled and motivated regulators, given the changed role of regulatory enforcers from inspecting specific items to certifying performance.

The move to performance-based regulations has often come about in parallel with changes to the system for appointing building inspectors who are responsible for certifying firstly that the building design meets code requirements and secondly that the building is safe to be occupied once it is constructed. ${ }^{1}$ What was once a function of government employees, building inspection has been privatised as a profession despite inspectors themselves retaining public accountability for building quality. This change has occurred in multiple jurisdictions including Australia and the UK as we will describe further below.

\subsection{Public Accountability}

Accountability is fundamental in public administration. Public servants are answerable for their performance, but questions arise as to which stakeholders are legitimate sources of control and what are legitimate performance expectations. Traditionally,

\footnotetext{
${ }^{1}$ In some jurisdictions, these tasks are performed by a building surveyor (rather than inspector). Interim physical inspections during the construction process may be performed by a contracted building inspector working for the surveyor. We use the term "inspector" to mean the person with the legislated responsibility for checking compliance and issuing permits.
} 
public servants were answerable to parliament and the courts, but this is no longer the case. It has been pointed out that "in a complex administrative state, characterised by widespread delegation of discretion to actors located far from the centre of government, the conception of centralised responsibility upon which traditional accountability mechanisms are based is often fictional" [10, p. 38].

To address this complexity, Romzek and Ingraham [9] propose a four-factor typology of public accountability that supports investigation of regulatory action through an accountability lens. The public administration accountability framework comprises legal, bureaucratic, professional and political accountability. Building inspectors are no longer public servants; i.e., they are not employed by government, and yet they fulfil a statutory function, enforcing the building regulations by certifying firstly, that the design and later, the building itself, meet the relevant codes. As such, the public interest is fundamental to their activities and the public administration accountability framework provides a useful perspective on how their role is defined and how it works in practice. Note that in the context of building inspectors, the framework is being applied to study the inspectors' accountability for their actions, not the compliance of industry with regulations which is a separate issue.

Legal accountability describes how the work of the building inspectors is driven by statutory rules defining their role, responsibilities and mandated qualifications. Bureaucratic accountability is concerned with other sets of rules that are used by the building inspectors in carrying out their work. These are the regulations and codes that the building sector must comply with. Building inspectors draw on these in assessing compliance and so issuing permits. Professional accountability drives building inspectors to exercise their professional judgement in the regulation implementation process in accordance with professional norms. Examples of mechanisms to ensure professional accountability include codes of conduct.

Finally, political accountability is the responsiveness of building inspectors to political constituencies which may include the general public, building occupiers, the construction sector generally, elected officials, statutory agencies or other arms of government, future generations and of course their client who is funding their inspection services. Political accountability aims to ensure participation and approval of those who are regulated and society at large as a form of feedback to the regulatory system [1]. As Romzek and Dubnick point out, "while political accountability systems might seem to promote favoritism and even corruption ... they also serve as the basis for a more open and representative government" [8, p. 229]. In the context of building inspectors, their private sector status brings a strong implication that political accountability to their clients is significant as we shall see.

The process of assessing accountability performance requires three phases: (1) provision or obtaining information (the accountable party reporting on their actions), (2) review and assessment (discussion and/or evaluation of actions taken) and (3) consequences (reward or sanction based on performance) [1]. Whilst the forum that deals with these phases may vary according to specific circumstances, all three are required and a culture of accountability may fail in the absence of established information provision processes, credible and ratified review process, as well as lack of consequences if accountabilities are not executed appropriately. 


\subsection{Grenfell Tower}

On 14 June 2017, a fire broke out in the 24-storey Grenfell Tower building in West London, resulting in 72 deaths and more than 70 injuries. Investigations revealed that the fire started with a malfunctioning refrigerator on the fourth floor, but it spread quickly to the entire building as a result of recently retrofitted combustible cladding on the building exterior [3].

In the UK, compliance with the relevant building regulations is primarily the duty of the person carrying out the building work, but, unless the work is defined as low risk, independent building control oversight is required. This was the case for the Grenfell Tower modifications to install new cladding. This service can be provided in two ways. The duty holder can either approach their local authority (i.e. local government) and have them provide the building control service for a fee or choose the approved inspector route. In the second case, a private sector practitioner is hired to provide inspection services on a commercial basis. The inquiry into the UK construction regulation following the Grenfell Tower disaster highlighted that "part privatisation of this regulatory function has created a unique competitive environment and has introduced unintended consequences" [4, p. 54]. Most authorised inspectors work for small organisations that rely on their relationships with builders and building construction companies for their ongoing work. The accountability framework discussed above provides a way to examine these arrangements.

Legal accountability is weak with no oversight of the quality of inspectors' work in place and "no legislative requirements that set standards of competence or training for building control inspectors" [4, p. 55], either in the public or private spheres. Bureaucratic accountability is facilitated by the large volume of codes and standards and the drawings submitted to inspectors for review, so in most cases there will be large volumes of data available for them to consider. However, the lack of any checking or audit mechanism for inspection activities means that there are typically no consequences for building inspectors if they fail to correctly consider this information. Professional accountability is also weak but increasing, with efforts afoot to professionalise these workers, including development of professional standards and formal tertiary qualifications. Professional standards would not only clarify for building inspectors exactly what is required; they would provide the basis for auditing building inspection activity and so enable consequences of accountability failings to be instituted.

Currently, building inspectors are largely driven by political accountability, i.e. direct consideration of stakeholder interests. This is not necessarily problematic, depending on whose interests prevail. The inquiry into UK building regulation postGrenfell [4] found that, while introduction of this arrangement had driven down costs, inspectors have a conflict of interest and experience a "difficult trade-off", failing to gain work if they do not approve more risky designs. Inspectors no longer act as impartial checkers of building safety, but rather "become far too embedded in supporting the building design process rather than being an impartial rigorous verifier of buildings safety" [4, p. 54]. The inquiry also reported "repeated concerns 
expressed about the commercial pressures associated with rigorous enforcement of fire safety requirements" [4, p. 55]. In summary, in many cases, the inspectors are effectively accountable to the very parties whose work they should be checking for compliance and face significant consequences if they fail to act in accordance with this accountability. This is not consistent with the best public safety outcomes and is an indicator of a systemic accountability gap in the sector.

Outsourcing of building control and other systemic inspection problems contributed significantly to the loss of 72 lives at Grenfell. The modifications to Grenfell Tower that covered the refurbished building in flammable cladding were approved by a building inspector working for the local authority. In evidence to the ongoing formal inquiry into the circumstances of the disaster, the inspector has admitted that his work fell below the standards of a reasonably competent inspector, ${ }^{2}$ yet he pointed out that at the time he was responsible for reviewing up to 130 projects. $^{3}$ Site inspections were carried out on behalf of the local authority by a contracted inspector who said his remit was not to check whether work met regulations ${ }^{4}$ or matched architects' drawings but rather to check that the work was neat and tidy. ${ }^{5}$

At the time of writing, the Grenfell Inquiry is ongoing. Privatisation of building inspection is only one of the weaknesses in the existing UK building quality control framework that has been revealed by the disaster. One key structural improvement is the imminent move of regulatory responsibility for buildings to the UK Health and Safety Executive which successfully performs this function for many other hazardous industries. It can only be hoped that this heralds a significant cultural and structural shift in public accountability for building quality in the UK.

\subsection{Incidents in the Australian Building Sector}

There have been two significant fire events in Australian high-risk buildings in recent years. No fatalities or injuries have resulted, but these are all near miss incidents that could have had much more serious consequences similar to the Grenfell case. The Lacrosse Building fire in Melbourne in 2014 affected hundreds of occupants who needed immediate evacuation and accommodation [2]. In early 2019, fire spread along the side of the Neo200 building (also in Melbourne) which used combustible cladding similar to the material used in the Grenfell Tower. Problems are not confined to Melbourne or to cladding. In 2018, hundreds of residences of the 36-storey Opal

\footnotetext{
${ }^{2}$ Transcript of Proceedings, Grenfell Tower Inquiry (Day 46, Sir Martin Moore-Bick, October 1 2020), 100 (J. E. Hoban).

${ }^{3}$ Transcript of Proceedings, Grenfell Tower Inquiry (Day 45, Sir Martin Moore-Bick, September 30 2020), 111 (J. E. Hoban).

${ }^{4}$ Transcript of Proceedings, Grenfell Tower Inquiry (Day 42, Sir Martin Moore-Bick, September 24 2020), 153 (J. White).

5 Transcript of Proceedings, Grenfell Tower Inquiry (Day 42, Sir Martin Moore-Bick, September 24 2020), 171-172 (J. White).
} 
Tower apartment building in Sydney were evacuated on Christmas Eve because structural cracking was observed in the building [12].

Building regulation is a state responsibility in Australia so there are variations in the details between states, but the states where the above events occurred operate systems that are very similar to that in the UK described above. Regulations are performance-based, and building inspection has been partly privatised. Building inspection can take two routes at the discretion of the builder, and certification is required, covering both the design and the completed building. Furthermore, increasing privatisation of regulatory enforcement has been found to result in a decline of accountability [13]. Following the Lacrosse fire and in the knowledge of other problems regarding counterfeit materials in the building supply chain, a national review of compliance and enforcement systems in building and construction was instigated in 2017 [11]. The review found multiple issues with the building inspection system that can be usefully summarised using a public accountability framework.

Shergold and Weir highlighted major problems with the legal accountability of private building inspection activities saying, "it is not just the conduct of private building surveyors that contributes to the problems, but also the lack of regulatory oversight of their conduct and, more importantly, the absence of a cohesive and collaborative relationship between state and local government and private building surveyors" [11, p. 14]. When it comes to bureaucratic accountability, they reported that decisions are based on documentation provided but, in practice, preparation of as-built plans is far from the norm and, as such, occupancy permits are often granted on the basis of out of date information. This means that changes to the approved design occur frequently without independent certification.

Professional accountability has also been weak. The review noted that " $[\mathrm{m}]$ any private certifiers are individuals of high integrity" [11, p. 14]. But they have acted as individuals with little support provided by the system. They face political accountability in addressing "the conflicting demands they face from their clients, the regulators and the insurers" [11, p. 14]. The review was told that when inspectors try to undertake enforcement action they are not supported by government and "on occasion, attention turns to their own conduct and they find themselves the subject of complaint and criticism" [11, p. 14].

With the strongest accountability being to their clients who they depend on financially, it is hardly surprising that investigations into specific incidents reveal a lack of regulatory enforcement. Following the Lacrosse apartment fire mentioned earlier, the building surveyor was referred for disciplinary action to the Building Practitioners Board on the basis that he could not have been satisfied that the building work met the relevant regulatory requirements when he issued the building permit. After various legal proceedings, he was found to be liable for the cost of repairs to the building, along with the architect and the fire engineer.

To address these issues, the review recommended statutory controls to mitigate conflict of interest, development of a code of conduct for building inspectors, mandatory reporting obligations regarding regulatory breaches and increased collaboration between building agencies and privatised inspectors on enforcement matters. 
Changes are being made in these areas in various states including new bureaucratic accountability support by issuing templates for inspectors to use, a new code of conduct providing not only professional norms but also a basis for enforcement, i.e. consequences for accountability failure. It is too soon to be able to assess the impact of these changes, but viewed through the framework of accountability types and processes, they are moves in the right direction.

\subsection{Discussion}

As we know from studies of regulation in other sectors, having skilled and competent regulators is critical in successfully enforcing performance-based regulation. In the building sector, we find that despite its criticality in ensuring public safety in highrise apartments, building inspection is not a popular career choice. In Australia and the UK, the average age of building inspectors is over 50 and there is no adequate career pathway leading to this important role. Given the current arrangements, it is easy to see why this is not a popular career choice within the construction sector. This needs to change to attract the best people to this critical role.

Too often in the wake of accidents, the focus has been on building inspectors themselves as we see with the liability findings in the Lacrosse case. Our analysis suggests that the problem is more structural. If building inspectors are to successfully take on the challenge of their important role, they must be better supported. There is a need to create a simple structure of public accountability for building inspectors that draws on all four public accountability types.

From a legal accountability perspective, the place of the building inspectors needs to be reinforced in legislation, including their authority to take appropriate enforcement action. Bureaucratically, there must be procedures in place for government agencies to support their frontline enforcement representatives, i.e. building inspectors, in doing their job. If local government is not able to provide such support, then there is a case for larger structural changes as we have seen in the UK with building regulation moved to an agency with more experience in regulating system safety in hazardous industries. In addition to support, comes the need for formal auditing of performance in some way to ensure that enforcement standards are maintained.

When it comes to professional accountability, improvements are also needed including articulation of a clear set of professional standards and expectations and a system of peer support so that building inspectors are encouraged to act in a way consistent with the standards set. Specific training and licensing arrangements linked to professional standards would allow the costs associated with building inspection work to be linked to specific requirements and defended in the case of commercial pressure.

Since privatisation, building inspectors' primary political accountability has been to commercially focused building sector stakeholders. The changes suggested above are designed to rebalance the system. The safety of high-rise building occupants must play a stronger role in driving day-to-day activities of building inspectors. This 
will only happen if the work of building inspectors is overseen more closely by government, so the necessary political accountability is in place.

These problems have arisen in parallel with the part privatisation of building inspection, but if sufficient support and oversight is provided to ensure that enforcement standards are being maintained, there is no inherent reason why these inspection activities cannot be outsourced to the private sector. When it comes to enforcement, low-level activities such as persuasion and issuing notices can be done by licenced private sector professionals but strong links are needed into government to deal with cases that require escalating enforcement action and to ensure standards of inspection are met.

The justification for such changes is not only safety-related. When we look at building quality more broadly, the building sector as a whole is riddled with problems. A recent study of 212 residential multi-occupant building audits in Australia suggested a staggering $85.7 \%$ of the buildings had at least one identified defect with an average of more than 14 identified defects per building [5]. Reform is needed across the sector, but a strong enforcement system is a key part of any overall plan to lift building quality for both safety and commercial reasons.

\subsection{Conclusion}

The Grenfell Tower disaster must be a turning point in raising awareness about the problem of building safety. This case highlights many weaknesses in the sector, but here we have focused on outsourcing of the regulatory function of building inspection using the theoretical lens of public accountability. In effect, the building sector in both the UK and Australia has operated with little regulatory oversight and little enforcement since building inspection activities were partly privatised several decades ago. The reason lies not so much in the skills and competencies of individual building inspectors, but in the structure of the system that drives them to consider political accountability to other building industry stakeholders above all else as a result of weaknesses in other mechanisms for ensuring public accountability. This occurs despite clear evidence (in the form of accidents and near misses) that this approach is not adequate, particularly in relation to high-rise buildings. Building inspectors are left to work within a system in which weak public accountability mechanisms are inherent in the structure of the system itself.

As a result, there is a need to provide structural changes that ensure public accountability, with a focus on the end-users. This includes addressing factors linked to all four facets of public accountability-legal, bureaucratic, professional and political. Providing the necessary support and oversight mechanisms, via legal, bureaucratic and professional means, can serve to rebalance the political accountability of building inspectors away from commercial building sector interests and further towards the health and well-being of building occupants and users. While outsourcing has significantly contributed to the current situation, if government processes can more strongly 
support and supervise private building inspectors, this aspect of the structure does not have to be inherently problematic.

\section{References}

1. G.J. Brandsma, T. Schillemans, The accountability cube: measuring accountability. J. Public Adm. Res. Theory 23, 953-975 (2012)

2. G. Genco, Lacrosse Building Fire 673 La Trobe Street, Docklands on 25 November 2014 (2015)

3. GTI, Report of the Public Inquiry into the Fire at Grenfell Tower on 14 June 2017 (2019)

4. J. Hackitt, Building a Safer Future Independent Review of Building Regulations and Fire Safety: Interim Report (2017)

5. N. Johnston, S. Reid, An Examination of Building Defects in Residential Multi-owned Properties (2019)

6. B. Meacham, Toward Next Generation Performance-Based Building Regulatory Systems (2016)

7. B. Meacham, R. Bowen, J. Traw, A. Moore, Performance-based building regulation: current situation and future needs. Build. Res. Inf. 33(2), 91-106 (2005)

8. B.S. Romzek, M.J. Dubnick, Accountability in the public sector: lessons from the challenger tragedy. Public Adm. Rev. 47(3), 227-238 (1987)

9. B.S. Romzek, P.W. Ingraham, Cross pressures of accountability: initiative, command, and failure in the Ron Brown plane crash. Public Adm. Rev. 60(3), 240-253 (2000)

10. C. Scott, Accountability in the regulatory state. J. Law Soc. 27(1), 38-60 (2000)

11. P. Shergold, B. Weir, Building Confidence: Improving the Effectiveness of Compliance and Enforcement Systems for the Building and Construction Industry Across Australia (2018)

12. Unisearch, Opal Tower Investigation Final Report (2019)

13. J. van der Heijden, On peanuts and monkeys: private sector involvement in Australian building control. Urban Policy Res. 28(2), 195-210 (2010)

Open Access This chapter is licensed under the terms of the Creative Commons Attribution 4.0 International License (http://creativecommons.org/licenses/by/4.0/), which permits use, sharing, adaptation, distribution and reproduction in any medium or format, as long as you give appropriate credit to the original author(s) and the source, provide a link to the Creative Commons license and indicate if changes were made.

The images or other third party material in this chapter are included in the chapter's Creative Commons license, unless indicated otherwise in a credit line to the material. If material is not included in the chapter's Creative Commons license and your intended use is not permitted by statutory regulation or exceeds the permitted use, you will need to obtain permission directly from the copyright holder.

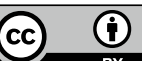

